\title{
Quantitative expression analysis of different cold-responsive (COR) and C-repeat binding factors (CBF) genes in wild and cultivated barley under cold acclimation conditions
}

\author{
Nahid Hazrati ${ }^{1}$, Mohammad Hasanzadeh ${ }^{2}$, Saime Ünver İkincikarakaya ${ }^{1}$, Canan Yüksel Özmen ${ }^{3}$ and Ali Ergül ${ }^{3 *}$ \\ ${ }^{1}$ Ankara University, Faculty of Agriculture, Department of Field Crops, 06110, Diskapi, Ankara, Turkey \\ ${ }^{2}$ University of Mohaghegh Ardabili, Faculty of Agriculture and Natural Resources-Moghan, Department of \\ Crop Production, Ardabil, Iran \\ ${ }^{3}$ Ankara University, Biotechnology Institute, 06135, Ankara, Turkey
}

*Corresponding author: ergul@ankara.edu.tr

\begin{abstract}
Cold stress affects plant metabolism and transcripts. The effect on plant metabolism was caused both by direct inhibition of metabolic enzymes at cold temperatures and by reprogramming the gene expression. The main objective of this study was to evaluate and identify of expression level of some cold-related genes under control and cold stress conditions in 11 spring/winter barley (Hordeum vulgare L.) varieties and 2 Hordeum spontaneum wild genotypes. For this purpose, expression profile of the main C-repeat binding factor $(C B F)$ genes along with expression profiles of the two cold-responsive $(C O R)$ genes in plants exposed to low temperatures $\left(+4{ }^{\circ} \mathrm{C}\right)$ were investigated. In parallel, measurements of leaf water potential of varieties were performed in control and at low temperature conditions. Results revealed that, the expression level changes of COR14b gene under cold conditions are more consistent with those of the upstream CBF9 gene expression levels in different varieties and time points rather than the other upstream gene (CBF1). The dehidrin8 ( $D H N 8$ ) expression level was also related to the CBF9 gene expression level and the decreased expression of the CBF9 gene resulted in decreased expression or non-expression of the DHN8 gene. Based on results, it could be said that CBF9 interacts with CBF1 to regulate $D H N 8$ expression. Wild genotypes showed statistically insignificant expression increment for investigated genes in days 1 and 8 of stress. This result is an indicator of the increase at expression levels in the stress genes of more tolerant varieties.
\end{abstract}

Key words: Cold acclimation; Barley; Cold responsive genes; Real-time PCR; CBF genes; COR genes.

Abbreviations: CBF_C-repeat binding factor; COR_Cold-responsive; DHN8_Dehydrin 8; CRT/DRE_C-repeat/dehydration-responsive element; GAPDH_Glyceraldehyde-3-phosphate dehydrogenase; P5CS_Pyrroline-5-carboxylate synthase; Fr-1_Frost resistence1; VRN1_ Vernalization1

\section{Introduction}

Barley, from Gramineae family, is an edible annual plant which has the highest ability to regenerate among the cool climate cereals. Barley varieties are classified as spring or winter types, depending on their planting date. The cultivated barley includes Hordeum vulgare distichum (two rows) and $H$. vulgare hexastichum (six rows) with the chromosome number of $2 n=$ 14. The number of chromosomes in wild barley species is $2 n=$ 14, 28 and 42 (Wang and Huang, 2002; Sheidai et al., 2009). Haploid cells of the barley contain about $5.5 \mathrm{pg}\left(1 \times 10^{-12} \mathrm{~g}\right)$ DNA at a size of $5.3 \times 10^{9}$ base pairs and $50-60 \%$ of the genome including the repetitive sequences (Rimpau et al., 1980; Gozukırmızı, 2003). Prominent genetic sources in barley cultivation and breeding programs are winter and spring varieties, and wild barley gene pools. Winter varieties are planted especially in regions with mild winters but exposed to cold climate in the winter period. Spring varieties are used for spring planting in regions where winters are harsh (Dawson et al., 2015). Wild relatives of barley are recognized as valuable sources of novel gene alleles. In different types of wild barley, stress tolerance is reported to be changed from genotype to genotype, and some show higher or lower tolerance in terms of specific stress tolerance (Dawson et al., 2015; Shahmoradi and Mozafari, 2015). The wide ecological spectrum of wild barley differs in terms of soil type, temperature, water availability, and altitude, which creates plant populations with high diversity and high adaption potential to abiotic stresses (Eglinton et al., 1999). Therefore, it can be used as the main gene pool in barley breeding programs (Ceccarelli et al., 1995; Shahmoradi and Mozafari, 2015). In wild barley, the geographic distribution of genetic and phenotypic diversity largely follows a natural separation by distance pattern, although it has been revealed that local adaptation through 
natural selection also has a significant effect on wild barley diversity (Schmid et al., 2018).

Plant productivity is largely influenced by environmental factors such as drought, high salinity and low temperatures. To survive under stress, plants respond to these stresses at the molecular, cellular, physiological, and biochemical levels. Expression of various genes has been shown to be induced by these stresses in various plants (Dubouzet et al., 2003). Plants might increase their tolerance against cold at low temperatures without frosting, which is defined as cold acclimation (cold fit). Molecular studies of acclimatization have revealed complex structures and processes characterized by up or down regulation of hundreds of cold regulated genes.

The low temperature tolerance is primarily regulated by the $C$ repeat Binding Factor $(C B F)$ genes. The expression of the $C B F$ genes is induced by low temperature. These genes are known to be the key regulators of the signaling pathway in the majority of plant species and cereals and cause the expression of the cold responsive (COR) genes. CBF transcription factors, often define C-repeat/dehydration-responsive element (CRT/DRE) motifs which are the regulatory regions of the COR genes containing a conserved CCGAC sequence as a binding site of CBF proteins (Pecchioni et al., 2014; Park et al., 2015). $C O R$ and $D H N$ (dehydrin) are structural proteins that function to stabilize lipid bilayers in cellular membranes against freezing damage. CBFs also play a role in promoting proline production by regulating the proline biosynthetic enzyme P5CS (Pyrroline5-carboxylate synthase) and soluble sugars such as sucrose, raffinose, glucose and fructose to high rates (Wang et al., 2018).

QTL mapping studies in barley and wheat have revealed that a large number of phenotypic differences related to cold tolerance, have been regulated by the two Fr-1 and Fr-2 (frost resistance) QTLs. The Fr-1 locus on chromosome 5A was found to harbor the VRN1 gene, while the $F r$-2 locus contained a cluster of at least 11 CBF genes in wheat and diploid barley, also known as dehydration responsive elements (DRE-binding factors) located on the long arm of chromosome $5 \mathrm{~A}$ (Galiba et al., 2009; Tondelli et al., 2014; Ahres et al., 2020). FR-2 CBFs belong to two phylogenetic groups - HvCBFIII and HvCBFIV (Badawi et al., 2007; Dhillon, 2012). The HvCBFIII subgroup includes CBF12, CBF15, CBF16, CBF3, CBF6, CBF10 and CBF13. The CBF2, CBF4, CBF9 and CBF14 genes belong to the HVCBFIV subgroup. All FR-2 CBFs respond to cold except CBF3, CBF6, CBF10 and CBF13 (Dhillon, 2012). Additional CBFs are dispersed on other 13 chromosomes of barley, which include CBF1, CBF5, CBF7, and CBF11 (Skinner et al., 2006).

Expression level analysis in cereals explains the complex arrangement of $C B F$ genes. The activation of these genes is influenced by genotype, temperature and light factors (Campoli et al., 2009; Novak et al., 2016; Ahres et al., 2020). Among the cold responsive factors, COR14b is well characterized in cereals. This gene may have different responses in frost-sensitive and frost-tolerant plants under the laboratory and field conditions during cold acclimation (Crosatti et al., 2008; Kosova et al., 2013; Kalapos et al., 2017). It is well established that, the development of the cold adaptation is linked to the accumulation of COR transcripts (Dhillon et al., 2010; Gulyás et al., 2014). In this regard, genetic linkage between the protein or transcript accumulation and tolerance to cold has been shown for WCS120 in wheat and
COR14b in barley (Holková et al., 2009; Kosova et al., 2013; Kruse et al., 2020; Ahres et al., 2020; Kosova et al., 2021).

As the cold of onset of winter is one of the stresses negatively influence the germination and establishment of the winter barley, late frosts and cold temperatures also cause stress and damages in spring cultures. Nowadays, the use of wild barley in breeding studies as a source of cold tolerance genes has been increased. However, considering the large number of $C B F s$ in the genome of the cereals including barley, it is possible to study the function of the individual genes with various experiments. Better definition of the events that occur in the barley plants exposed to the cold, is of great importance to identify the different components of adaptation in grains. For this purpose, we performed experiments on identification of some of the cold-related genes expression under control and cold stress conditions in eleven barley varieties and two wild genotypes.

\section{Results}

In the present study, the expression profiles of a number of cold-induced genes including HvCOR14b, HvCBF9, HvCBF1 and HvDHN8 (Table 1) were studied in 11 cultivated barley varieties and 2 wild genotypes under control and low temperature conditions. Considering that CBF1 and CBF9 genes in previous studies had shown more transcript changes under cold stress so, they were selected as the studied genes exist in HvCBFIII subgroup. Expression changes were investigated by qRT-PCR, using GAPDH (housekeeping) control gene. According to qRT-PCR results, expression levels of selected genes were found to be different in the stress conditions from that of control ( $p<0.05$ ANOVA-BH).

\section{Expression level of the CBF1 and CBF9 genes under cold stress conditions}

In day 1 of the cold stress, CBF1 gene expression analysis showed different induction levels in different genotypes (Fig 1.). While the CBF1 gene showed a statistically significant increase in Yalın and Özdemir varieties in first day of the cold stress, its expression decreased or did not change in other varieties (Fig 1.).

CBF9 gene showed different profiles in cultivated varieties and wild genotypes at the first time point of the stress, and exhibited low expression profiles in days 1 and 8 of stress. While this gene showed an increase in Tarm variety and wild genotypes of $H$. Spontaneum 3 and $H$. Spontaneum 7 in first day of stress, this rate was declined in day 8 of the cold stress or demonstrated a statistically insignificant increase in mentioned genotypes. In day 8, the CBF9 gene transcript was significantly increased only in Özen spring variety compared to the first day. Among the varieties studied, only Zeynel ağa variety showed a significant reduction in the CBF9 gene at both measurement time points, while in Orza variety, the significant reduction which was recorded at the CBF9 gene transcript level in first day was changed to the non-different level in day 8 of cold stress.

Considering the expression levels of the COR14b, it could be noted that expression of the CBF9 gene was increased in cold tolerant varieties and decreased in susceptible ones. Also, varieties showing reduction in the CBF9 expression had slight expression of the COR14b. Since more significant transcript 
changes were seen at the first time point so, this time point seems to be more logical to apply in gene expression analysis studies. The expression levels of the CBF1 and CBF9 genes have been depicted comparatively in different genotypes in Figure 1 and 2, respectively.

In the present study, it was revealed that, the expression changes of COR14b gene under cold conditions were more consistent with the changes of the upstream CBF9 gene expression levels in different varieties and time points rather than the other upstream gene (CBF1). It was also found that the COR14b gene expression was more related to the CBF9 gene induction, than to the CBF1 gene. CBF9 expression levels were also associated with the $D H N 8$ gene expression levels, and a decrease in the CBF9 gene expression led to the decrease in the $D H N 8$ gene expression or non-expression of this gene. In addition, it was found that the CBF9 interacts with the $C B F 1$ to regulate the $D H N 8$ expression levels so that, in the studied varieties, the CBF9 expression appeared when the CBF1 gene expression level was low or there was no change in its expression. It has also been determined that the CBF9 was induced slowly and at low levels in comparison with the CBF1 gene (Fig 1 and 2).

\section{Expression levels of the COR14b gene under cold stress conditions}

Analysis of the expression levels of the COR14b at different time points indicated significant increase in expression of this gene in the most varieties in first day of the cold treatment. Thus, while this gene showed reduced expression levels in Orza variety (statistically insignificant), it showed increased expression levels in all other varieties. This gene exhibited the highest expression in Özen spring variety by 624.55 fold increase, followed by 391.6 and 84.6 fold increases in ince and Yalın as winter varieties, respectively (Fig 3.). In day 8 of stress, the significant induction of the COR14b gene was detected in Aydan hanım variety ( 3.8 fold) while the most induction (nonsignificant) profile was shown in Özen spring variety (76.9 fold). Also, an increased transcript profile (10.7 folds) was shown in wild $H$. Spontaneum 3 but this increase was not statistically significant at transcript level. This gene showed 11.0 and 6.6 fold expression decreases in Ünver and Özdemir varieties, respectively, while expression reduction of Zeynel ağa and Keser transcripts was insignificant in day 8 of stress (Fig 3.). Since the COR14b gen profiles showed more significant changes in day 1 among the studied varieties so, it would be more reasonable to consider this time point in gene expression analysis. Interestingly, in first day of stress, Orza, Zeynel ağa, Aydan hanım, Keser and Özdemir among the winter varieties showed the lowest induction profile of the COR14b gene respectively, while the same varieties revealed significant negative gene expression profiles for the CBF1 and CBF9 genes or at least one of them. Among the winter varieties, the most COR14b expression values were appeared in Ince and Yalın varieties. Expression levels of the COR14b gene (fold change) in different genotypes compared to the control GAPDH gene has been shown in Fig 3.

\section{Expression levels of the DHN8 gene under cold stress conditions}

Expression analysis of the $D H N 8$ gene revealed that in first day of stress, this gene showed an increased profile in majority of studied varieties and genotypes, and the most transcripts of this gene have been observed in Özen spring variety (17.4 fold). Also, decreased expression profiles of the DHN8 were identified in Keser, Orza and Özdemir varieties. In day 8 of stress, low level changes were observed in this gene with the most induction level in Yalın (7.13 fold), Kalayıcı (5.6 fold) and Özen (4.7 fold) varieties. The least expression levels were determined by 5.7 and 3.7 fold reductions in Özdemir and Keser varieties (Fig 4.). The expression levels of the DHN8 gene in different genotypes have been comparatively shown in Fig 4. Also, transcript levels of investigated genes in Özen, Aydan hanım, Ince, Yalın, Kalayıcı, Tarm, Keser, Orza, Zeynel ağa, Özdemir, Ünver varieties and also $H$. spontaneum 3 and $H$. spontaneum 7 genotypes after day 1 and 8 of cold acclimation have been shown in Figure 5., respectively. Venn diagram of the genotypes with increased expression, decreased expression and no expression changes in at least one of the 4 genes, at the time points of day 1 and 8 have been depicted in Fig 7.

\section{Discussion}

Cold stress may lead to rapid induction of a number of transcription factors including AP2 domain proteins and CBFs, which subsequently activate expression of many cold responding genes (COR) (Chinnusamy et al., 2007; Zhu, 2016). COR14b, DHN5, and DHN8 harboring CRT/DRE motifs in their upstream regulatory region are considered as candidate $C B F$ target genes in cereals (Dal Bosco et al., 2003, Jeknic et al., 2014). Also, it has been cleared that, these COR genes are expressed at higher levels in cold-tolerant genotypes (Dhillon et al., 2010).

In the present study, the expression changes of the CBF1, CBF9, COR14B and DHN8 genes in different winter and spring varieties and wild type genotypes have been studied in detail.

\section{Winter varieties}

In our research, it was distinguished that the COR14b gene induction was linked to the expression of the CBF1 and CBF9 genes in winter and wild genotypes, and increased expression levels of these genes enhanced the expression level of COR14b gene and their reduced expression, decreased the expression of the target COR14b gene. Obtained results are in accordance with findings of Jeknic et al. (2014) and Ahres et al. (2020). Accordingly, in all cases where there was a decrease in expression of the COR14b gene, we observed a decrease in expression of both CBF1 and CBF9 genes in first or eighth day of stress with the exception of one case in Özdemir variety in eighth day of the stress, which showed reduced value of the COR14b expression relative to the control, while it showed unchanged expression values for CBF1 and CBF9 genes at that time point.

In addition, in varieties with decreased expression levels of COR14b, the DHN8 gene showed the same expression reduction, and when the COR14b transcript was over expressed, the $D H N 8$ also showed increased expression profile. Accurate assessment of the data revealed that, the $D H N 8$ gene expression profile was associated with that of the CBF1 gene. In cases there was an increase in both CBF1 and CBF9 transcripts, or in cases there was an increase in one of these $C B F$ transcripts while no expression difference in another one, 
an increase in DHN8 gene expression was observed. In this regard, our findings are consistent with Soltesz et al. (2013). Furthermore, when there was a decrease at the expression levels of these $C B F$ genes, the expression level of the DHN8 gene appeared to be decreased or not expressed at all. Ince and Yalın varieties showed the highest COR14b gene transcript levels, by 391.63 and 84.64 fold increases, respectively, in comparison to other winter varieties (Fig 3.). Also these varieties have been determined to show the lowest leaf water potential decrease during 10- days of cold stress period. In general, these two varieties showed tolerance against cold at different time points of stress. On the other hand, Keser, Orza and Zeynel ağa varieties showed similar transcript level changes in day 1 of stress, and they were the most affected by cold in first day among the winter varieties. In day 8 of stress, Orza variety showed a more adapted behavior to cold, without differing transcript levels of the genes investigated. However, Keser and Zeynel ağa varieties showed a more sensitive profile than that of day 1 , showing expression decreases in the COR14b gene in day 8 of stress (Fig 5. $g, h, i)$ and they were shown not to be compatible with cold. Results obtained in the study confirm that stress adaptation phenomenon in plants acclimated to cold can be provided by multiple defense systems. These systems can also protect cold acclimated plants from other stress conditions. In general, by transferring the major key gene (s) such as CBF1 and CBF9, engineering of stress tolerant plants can be an effective approach to minimize cold stress damage.

\section{Spring variety}

Özen, being the recommended variety for spring cultivation, showed an increased expression levels in the COR14b gene, with decreased profile in the CBF1. This may be due to the high expression level in the $V R N-1$ gene in this variety. The conditions of exposure to non-freezing temperatures is an important factor for both cold acclimation and vernalization and suggests a potential connection between these two processes. In varieties with winter growth habit (vrn-1 allele), plants show very low $V R N-1$ transcript levels until vernalization. In contrast, the spring varieties ( $V r n-1$ allele) express $V R N-1$ at high levels. Flowering is initiated when the $V R N-1$ transcript reaches its critical level (Loukoianov et al., 2005). Dhillon et al. (2010) used two diploid wheat (Triticum monococcum) mutants with deletions in the main vernalization gene (VRN-1) that maintained in vegetative phase ( $\mathrm{mVP})$ and the other mutants carrying at least one functional $V R N-1$ copy (Mvp/2), exposed to $+4{ }^{\circ} \mathrm{C}$ temperature for 12 days, transcript levels for both varieties peaked in $32^{\text {nd }}$ hours in qRT-PCR experiment, and began to decrease slowly over the next 11 days. They found that homozygote $\mathrm{mVP} / \mathrm{mVP}$ plants never blossom, while plants bearing at least one functional $V R N-1$ copy $(\mathrm{Mvp} / 2)$ show normal blossoming and high $V R N-1$ transcript levels over long days. Mvp/2 plants showed that the transcript levels of cold-induced $C B F$ transcription factors were reduced compared to $\mathrm{mVP} / \mathrm{mVP}$ plants. Although it was shown that the DHN5 gene involved the same negative correlation with $V R N-1$ while, the $D H N 8$ gene was not significantly affected by the change at $V R N-1$ transcript level and this implies that all COR genes are not down regulated by $V R N-1$. Likewise, Oliver et al. (2013) observed similar expression patterns of VRN1 and COR14b ( 24 hours, $+4{ }^{\circ} \mathrm{C}$ cold treatment) in barley seedlings and they suggested that these genes could be probably affected by the action of $C B F$ transcription factors by mechanisms which take place in the early phase of cold climate. Also, Ergon et al. (2016), by investigating the effect of vernalization and VRN1 region on cold tolerance in Festuca pratensis reported that the transcript amount of the VRN1 gene showed increased expression profile in a positive correlation with the COR14b transcript amount. Different results obtained from the various studies reveal that this mechanism is really complicated. Results of our work on Özen variety are also consistent with those of Oliver et al. (2013). We concluded that at the end of 24 hours of cold treatment, severe CBF1 transcript decrease and COR14b gene increase appeared in Özen variety (Fig 5 . a) may be attributed to the increased amount of CBF group genes transcripts and induction of $C O R$ genes in first hours of the cold ( 3 hours) followed by rapid transcript reduction of the CBF genes. Although this variety showed a slight increase and/or decrease in expression levels in day 8 of stress compared to day 1 , and the severe expression decrease (in CBF1) or increase (in COR14b) were diminished (Fig 5. a), but in comparison with other varieties, there were more variations at the transcript levels. On the other hand, leaf water potential decrease of Özen variety at the end of the first day of cold treatment, can be associated with the low transcript level of the CBF1 gene in this variety. Since $C B F$ group genes are involved in the production of osmolites and sugar species, high water potential reduction in this variety may be the sign of less transcript proliferation in CBF group genes compared to other varieties at this time point.

\section{Wild genotypes}

$H$. spontaneum 3 and $H$. spontaneum 7 showed statistically insignificant expression increase in investigated genes in days 1 and 8 of stress (Fig 5. I, m). This result is a sign of increase at expression levels in the stress genes of more tolerant varieties. Also, the insignificant expression of the genes may also indicate the expression of these genes in control wild genotypes, too. Thus, by guarding against potential stress, when faced the stress, gene expression systems can easily gain tolerance. Vagujfalvi et al. (2000) reported that, while TaCOR14b accumulation is begin even at $18 / 15{ }^{\circ} \mathrm{C}$ in coldresistant wheat genotypes, it is not expressed in cold-sensitive ones, at all. So, the authors concluded that the temperature threshold of COR14b gene induction is higher in cold-resistant plants.

Correlation of CBF1 gene expression with leaf water potential In our study, it was found that the role of the CBF1 gene in response to cold stress is more related to the control of cellular water potential than the control of the downstream COR genes. By measuring the cellular water potential conducted in Keser, Özdemir, and Aydan hanım varieties for 10 consecutive days, it was found that changes at the expression levels of the CBF1 gene under cold stress were closely related to the leaf water potential changes (data not shown). According to these results, Keser, as winter variety with the high amount of water potential loss in first day of cold stress $\left(+4{ }^{\circ} \mathrm{C}\right)$ showed more decrease in CBF1 gene expression at that time point (Fig 6. a). 
Table 1. Real-Time PCR primer sequences (Fwd: forward primer; Rev: reverse primer).

\begin{tabular}{|c|c|c|c|}
\hline Gene name & $\begin{array}{l}\text { Gen Bank } \\
\text { (NCBI) no }\end{array}$ & Primer sequences & Primer reference \\
\hline HvCOR14b & AJ512944 & $\begin{array}{l}\text { Fwd 5'-TTGAGGATGTGAGCAAATGAG-3' } \\
\text { Rev 5'-TACATCGTCAATGACGAGACC-3' }\end{array}$ & Morran et al. (2011) \\
\hline HvCBF9 & AY785877 & $\begin{array}{l}\text { Fwd 5'-AGCACTACTGTCAACATGTAG-3' } \\
\text { Rev 5'-CCTTGATTTCGATTCATGGAG-3' }\end{array}$ & Morran et al. (2011) \\
\hline$H v C B F 1$ & AY785839 & $\begin{array}{l}\text { Fwd 5'-ATGGACGATGGTATGGACTTC-3' } \\
\text { Rev 5'-TGCACATGCATTAGTAGTTC-3' }\end{array}$ & Morran et al. (2011) \\
\hline HvDHN8 & AF043096 & $\begin{array}{l}\text { Fwd 5'-TGCTCCAGCGCCAGTGCAC-3' } \\
\text { Rev 5'-CGATCAAGCTCTGGGCTTGTG-3' }\end{array}$ & Campoli et al. (2009) \\
\hline GAPDH & & $\begin{array}{l}\text { Fwd 5'- CTGTTGTTGATCTGACTGTTA -3' } \\
\text { Rev 5'- TCCTCATCGACATAACCCAAA- 3' }\end{array}$ & \\
\hline
\end{tabular}

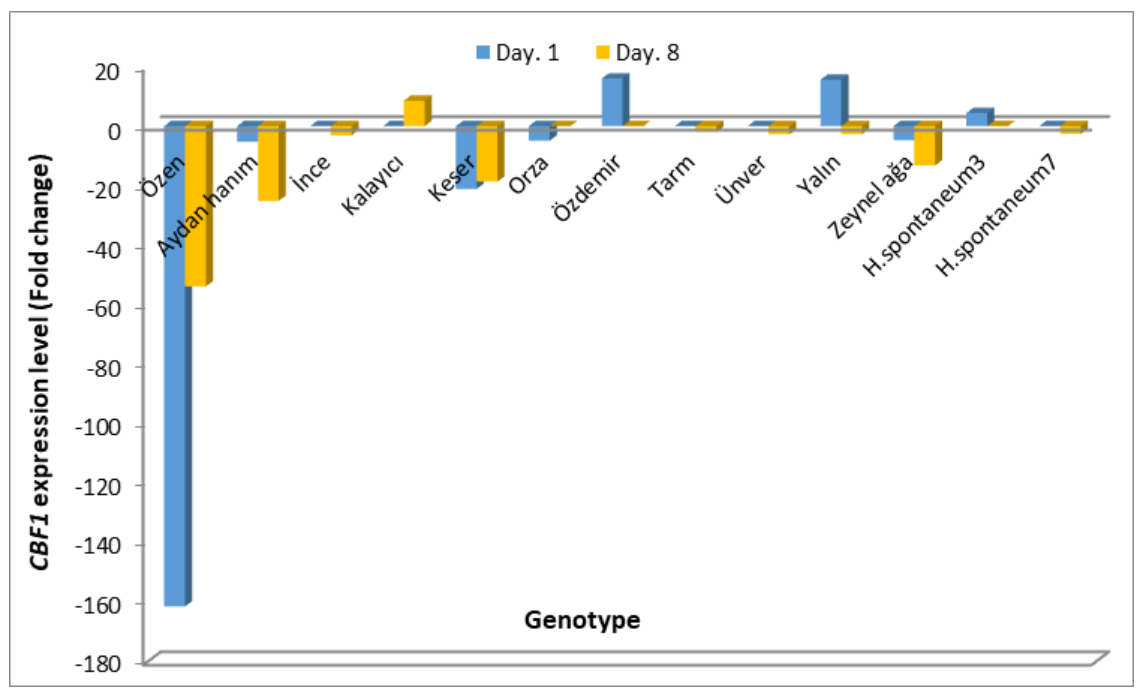

Fig 1. Expression levels (fold change) of the CBF1 gene comparatively in different varieties and wild genotypes with the GAPDH control gene in day 1 and 8 of cold acclimation treatment $\left(+4^{\circ} \mathrm{C}\right)$

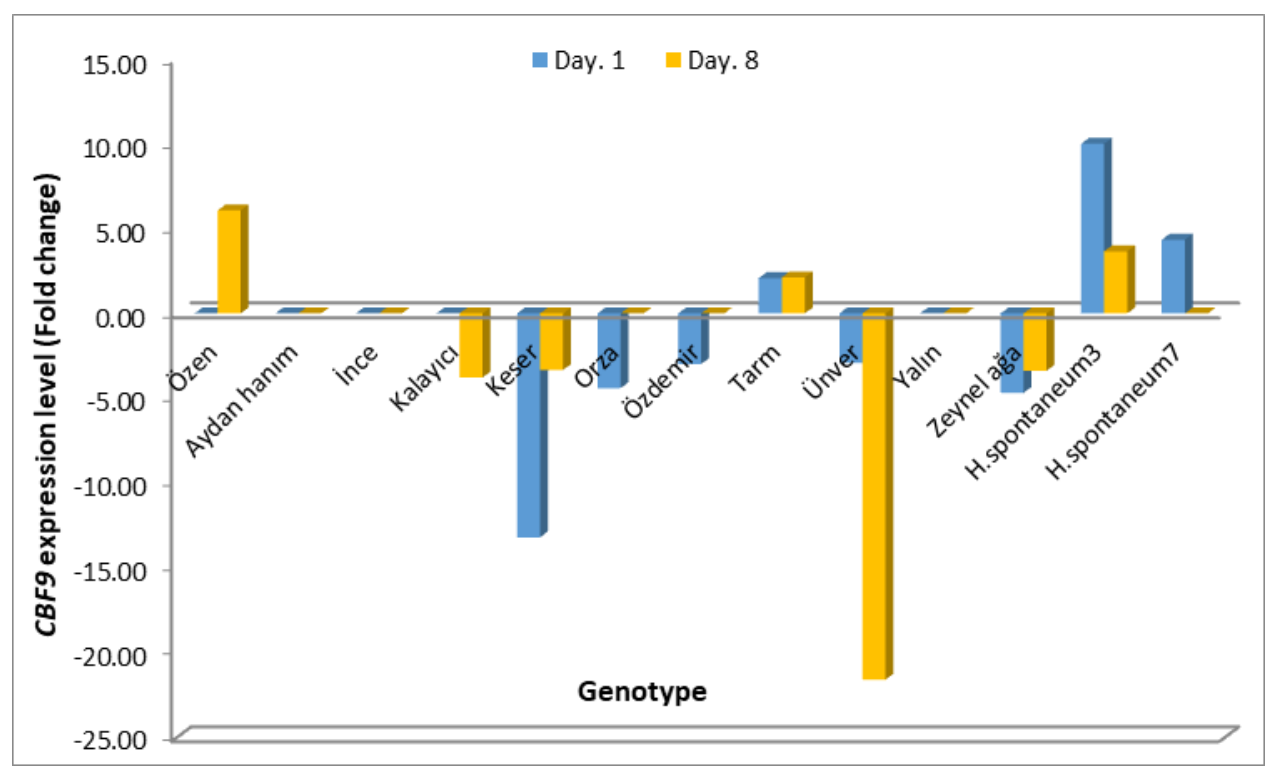

Fig 2. Expression levels (fold change) of the CBF9 gene comparatively in different varieties and wild genotypes with the GAPDH control gene in day 1 and 8 of cold acclimation treatment $\left(+4{ }^{\circ} \mathrm{C}\right)$ 


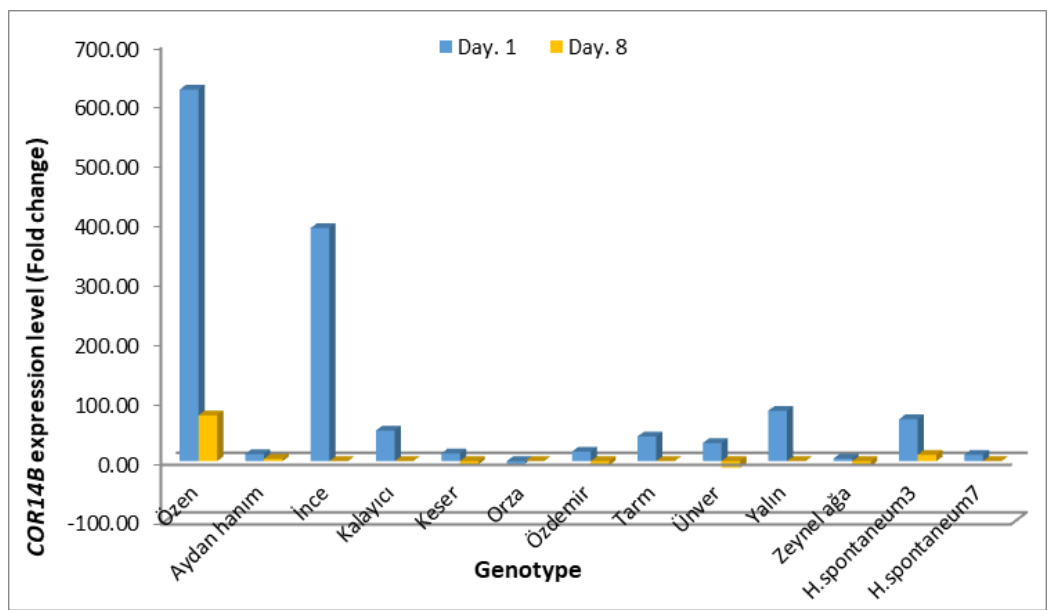

Fig 3. Expression levels (fold change) of the COR14b gene comparatively in different varieties and wild genotypes with the GAPDH control gene in day 1 and 8 of cold acclimation treatment $\left(+4^{\circ} \mathrm{C}\right)$

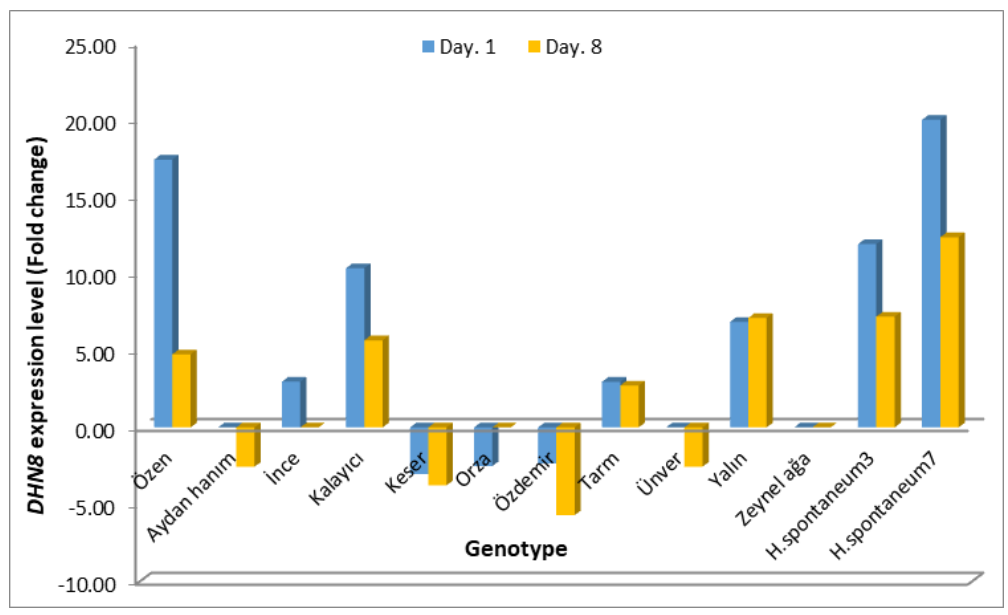

Fig 4. Expression levels (fold change) of the $D H N 8$ gene comparatively in different varieties and wild genotypes with the GAPDH control gene in day 1 and 8 of cold acclimation treatment $\left(+4{ }^{\circ} \mathrm{C}\right)$

In addition, Özdemir, as winter variety, with the high increase in expression of CBF1 gene in first day, showed lower rates of water potential loss in first day and this trend was also observed in day 8 of stress (Fig 6. b). Although Aydan hanım variety was placed among the varieties that are significantly affected by cold in first day of cold stress, induction of COR14b gene was increased in day 8 of stress and its tolerance increased against cold (Fig 5. b). Furthermore, Aydan hanım variety was determined to show the most water potential decrease in 10-day period of leaf-water potential measurements (Fig 6. c) along with significant expression reduction in CBF1. These results are consistent with the proper response of this variety to winter cultivation with additional irrigation for its cultivation, and are considered another reason for strengthening the theory of CBF1 major role in regulating cell water potential under stress conditions.

Previously, Hsieh et al. (2002) found that transgenic tomato plants expressing Arabidopsis CBF1 gene displayed higher water deficit tolerance. In addition, Gupta et al. (2012) reported that under control conditions (without stress), transgenic cucumber plants expressing Arabidopsis CBF1 gene and wild species showed no difference, while under chilling stress conditions, RWC (relative water content) in transgenic plants was significantly higher than that of wild plants. In the present work, it was found that the CBF1 gene increased plant cold tolerance by controlling the cell water potential rather than the modulation of the COR14B and DHN8 genes and also, indicated a higher adaptive ability in severe environments via the enhanced water retaining capacity.

\section{Materials and methods}

\section{Plant materials}

In our study; Kalaycı 97, İnce 04, Özdemir 05, Keser, Ünver, Aydan hanım, Zeynel ağa, Tarm 92, Orza 96, Yalın registered winter cultivated barley varieties, and Özen registered spring cultivated barley variety, and Hordeum spontaneum (NE 3) and H. spontaneum (NE 7) wild barley genotypes were used as 


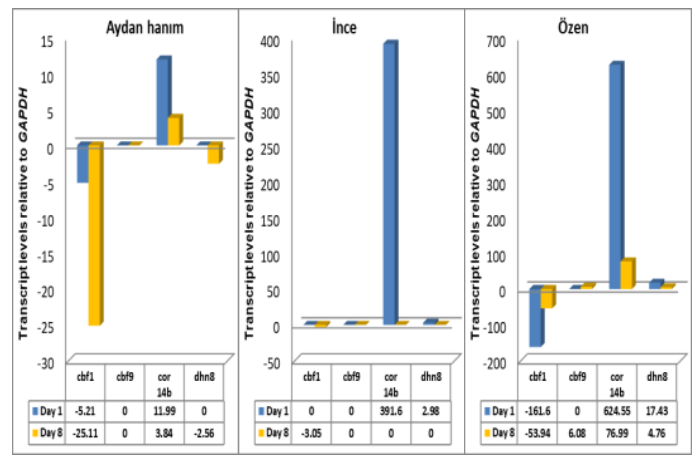

a)

b)
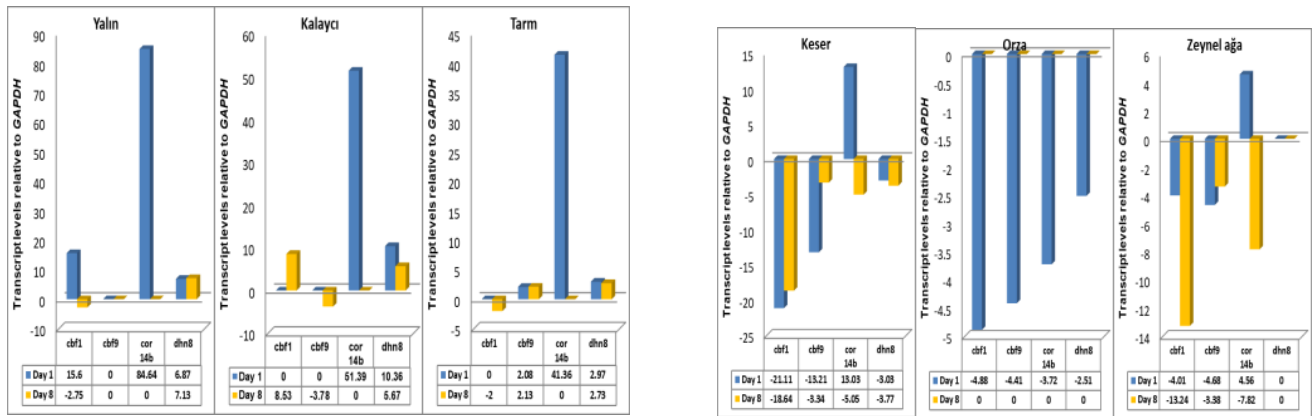

d)

e)

f)

g)

h)

i)

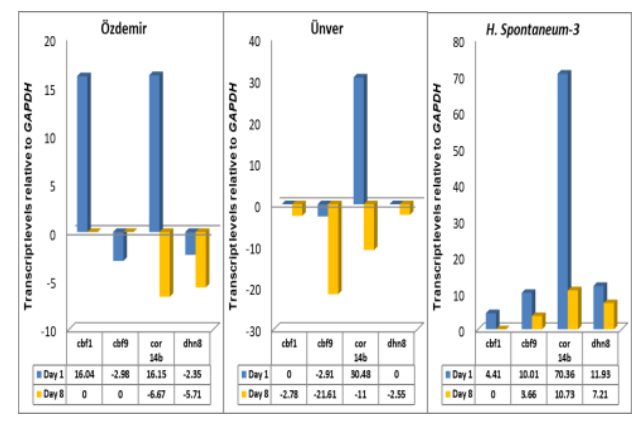

j)

k)

1)

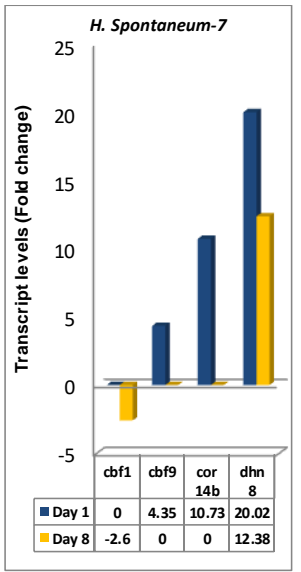

$\mathrm{m})$

Fig 5. Transcript levels (fold change) of investigated CBF1, CBF9, COR14b and DHN8 genes in spring and winter varieties Özen, Aydan hanım, İnce, Yalın, Kalayıcı, Tarm, Keser, Orza, Zeynel ağa, Özdemir, Ünver, and in wild genotypes H. spontaneum3 and H. spontaneum7 after day 1 and 8 of cold treatment $\left(+4{ }^{\circ} \mathrm{C}\right)$. The GAPDH control gene was used for normalization of the target genes. 


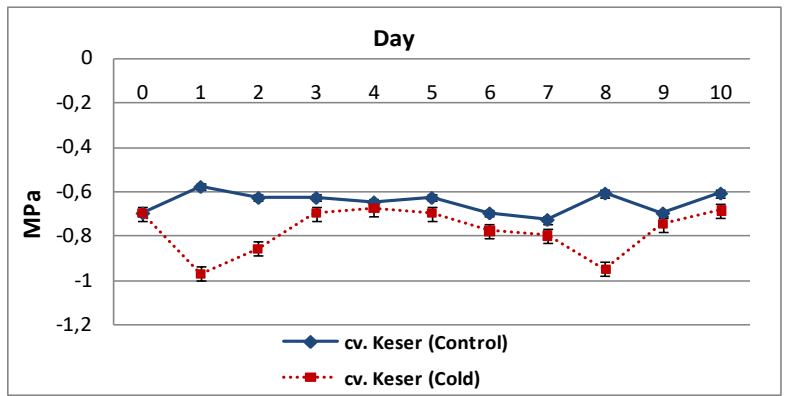

(a)

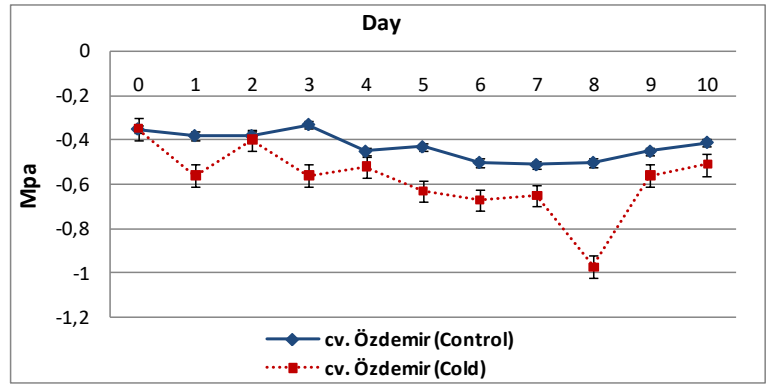

(b)

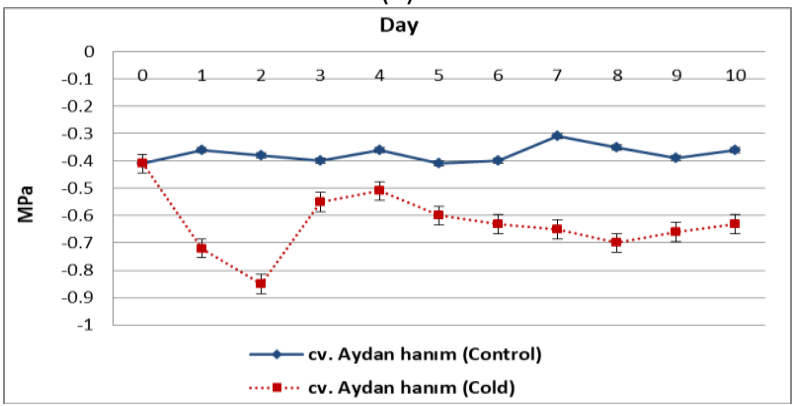

(c)

Fig 6. Variation of leaf water potential in cold stress application $\left(+4{ }^{\circ} \mathrm{C}\right)$ in Keser (a) Özdemir (b) and Aydan hanım (c) varieties for 10 consecutive days. Physiological measurements of leaf water potential (MPa value) of 5-weeks-old plants were performed in a pressure chamber (Model 600, PMS instrument Company, USA) on control plants and at the beginning of the cold stress application (Time 0) continued for 10 days with $24 \mathrm{~h}$ intervals with 3 replicates. The variation of leaf water potential was correlated with the variation of the CBF1 gene expression.
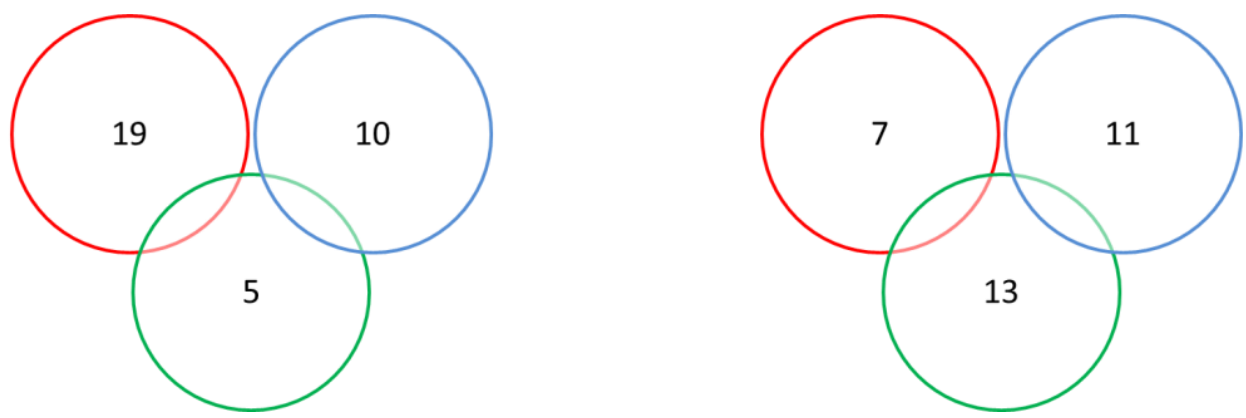

Fig 7. Venn diagram of the $1^{\text {st }}$ day time point (a), and the $8^{\text {th }}$ day time point (b); Number of genotypes with increased expression level (red cycle), decreased expression (blue cycle) and no expression change (green cycle) in at least one of the 4 genes. 
plant material. Seeds of the research were obtained from the Eskişehir Transitional Zone Agricultural Research Institute, and from Ankara Field Crops Central Research Institute, Turkey. Also, wild barley seeds were obtained from the Turkey Seed Gene Bank (Ankara, Turkey).

\section{Seed sterilization and germination}

Prior to the germination, seeds of two wild genotypes and eleven culture varieties of barley were sterilized in commercial hypochlorite sodium $5 \%(\mathrm{NaClO})$ for $20 \mathrm{~min}$ and then, the seeds were rinsed by constantly shaking for 20 min with tap water. The seeds were then inflated by leaving overnight in pure water at room temperature. Seeds were germinated on seed germination paper at $+24{ }^{\circ} \mathrm{C}, 16 / 8 \mathrm{~h}$ light/darkness and $60 \%$ relative humidity.

\section{Plant growth and cold stress treatment}

Germinated seeds were rolled 10 days later in nutrient papers (Anchor, SD3830) and then, were placed in Hoagland nutrient solution so that, the seedlings absorbed the nutrient through the paper while were not in direct contact with the solution. One week after, growing plants were removed from the rolled papers and transferred to the hydroponic conditions containing Hoagland nutrient solution for 3 weeks at $+17 /+13$ ${ }^{\circ} \mathrm{C}$, 16/8 h light/darkness, $240 \mu \mathrm{mol} / \mathrm{m}^{2} / \mathrm{s}$ photosynthesis photon light density, and $75 \%$ relative humidity. During this time, the Hoagland solution was regularly mixed and pumped, and was entirely replaced every ten days. Three weeks after, developed plants were subjected to cold acclimation for 10 days at $+4{ }^{\circ} \mathrm{C}$ while they were still in the hydroponic conditions and control plants were preserved at $+17 /+13^{\circ} \mathrm{C}$.

\section{Leaf water potential measurement (MPa)}

Using a pressure chamber instrument (Model 600, PMS Instrument Company, USA), leaf water potential of fully expanded leaves of 5-weeks-old cultivated barley varieties were measured based on the instructions of the manufacturer in day 0 (TO) and 10 consecutive days on control and cold treated plants. For this purpose, plants were cut into leaf blades to produce samples to be inserted immediately in the pressure chamber instrument. Meanwhile, nitrogen gas was slowly injected and appearance of the tiny droplets of water was assigned as the point of recording of the leaf water potential. Three replicated trials were performed for all the measurements. Using the t-test at $p<0.05$ significance level, $\mathrm{MPa}$ values were compared to that of control. After the measuring the MPa values, $0.5 \mathrm{~g}$ of the above mentioned leaf samples were wrapped in aluminum foil and immediately frozen in liquid nitrogen and refrigerated at $-80^{\circ} \mathrm{C}$.

\section{qRT-PCR (Real-Time PCR) amplifications and analysis}

Depending on the results of the leaf water potential analysis, leaf samples with time points of day 1 and day 8 having the significant leaf-water potential changes were used to evaluate gene expression profiles. Total RNA was isolated for analysis of the expression levels of the genes by qRT-PCR (Real-Time PCR) and RNA quality was tested by agarose gel electrophoresis using standard protocols. The Real-Time PCR method was performed in two steps. In the first step, cDNA synthesis was performed using the First Strand cDNA Synthesis Kit (Roche, Cat No. 04897030001), using RNA (2 $\mu \mathrm{g})$, Oligo dt Primer (50 $\mathrm{pmol} / \mu \mathrm{l}$ ) and water (PCR grade). In the thermal cycler (Biorad brand), the mixture was incubated at $65{ }^{\circ} \mathrm{C}$ for $10 \mathrm{~min}$ and then, immediately transferred on ice and the prepared reverse transcription mixtures (Transcriptor Reverse Transcriptase Reaction Buffer $(4 \mu \mathrm{l})$, RNase Inhibitor $(0.5 \mu \mathrm{l})$, dNTP mix $(2 \mu \mathrm{l})$ and Transcriptor Reverse Transcriptase Enzyme $(0.5 \mu \mathrm{l})$ ) were added and reverse transcription was carried out under the reaction conditions with the total content of $20 \mu \mathrm{L}$. After cDNA synthesis, amount of the obtained cDNA was measured and quantified by Nanodrop ND-1000 spectrophotometer and cDNA quality was tested by agarose gel electrophoresis. cDNA samples were then used as templates to quantify target gene expression levels.

In the second step, following the RT-PCR, the SYBR Green I (Roche) master kit was used. The qRT-PCR was performed in a $10 \mu \mathrm{l}$ of reaction mix that contained $3 \mu \mathrm{l}$ of cDNA $(500 \mathrm{ng} / \mu \mathrm{l})$, 0.4-0.8 $\mu \mathrm{l}$ of forward and reverse primers (10 pmol), $5 \mu \mathrm{l}$ of Light Cycler ${ }^{\circledR} 480$ SYBR Green I Master (Roche) and $\mathrm{ddH}_{2} \mathrm{O}$. The barley GAPDH control (housekeeping) gene was used for normalizing the values of the target genes. The sequence information for the selected primers and the housekeeping gene for the validation are given in Table 1. Primer pairs of GAPDH control gene were designed using the Primer3 software (http://bioinfo.ut.ee/primer3-0.4.0/).

The cDNAs containing samples of each primer and SYBR Green I (Roche) master kit contents were placed in specific platelets of the device. Then, plates were coated with Roche light cycler sealing foil and samples were run by selecting the optimal temperatures for each primer in the Roche Light Cycler 480 instrument. Serial dilutions were prepared at $1 / 10,1 / 100$, $1 / 1000,1 / 10000$, and $1 / 100000$, with a 6 logarithmic concentrations from the control cDNAs so that, standard curves could be plotted while Real-Time PCR reactions were being prepared and during the evaluation of the measurements, standard curves were plotted separately for each primer with the analysis program of Real-Time PCR instrument (the efficiency value was accepted between 1.7 and 2, and the slope value close to -3.3). Ct values were recorded using the peak profiles. Relative expression levels were calculated using the REST 2009 software program according to the 2- $\Delta \Delta C T$ (delta delta-Ct) algorithm. The qRTPCR conditions were optimized for high amplification efficiency $>95 \%$ for all used primer pairs. Confidence intervals (C.I.) were considered to be $95 \%$. In melting curve analyses, overlapping single peak images were obtained and the presence of dimers was checked. The expression levels of the CBF1, CBF9, COR14b, and $D H N 8$ genes were normalized by the expression level of the GAPDH control gene using the 2- $\triangle \triangle C T$ method (Livak and Schmittgen, 2001). The quantitative Real-Time PCR reactions were performed with three biological replicates and each biological sample was performed with three technical replicates. The expression levels of the studied genes were evaluated and more information about the association of genes to each other were achieved through multilateral comparisons of the expression levels of studied genes by considering the upstream and downstream genes relations

\section{Conclusions}

There were significant differences not only in opposite growth habits (spring and winter) but also among different winter 
varieties. As a result of cold stress application, distributions of studied genes in genotypes were examined. The highest number of genes with increased profile was found in $H$. spontaneum 3 wild barley genotype which no decreased transcripts were found. In Keser variety, the number of increased transcripts was 1 and the number of decreased transcripts was 7 and it had the highest number of genes with decreased profile. These results can be used in barley cold treatment studies and germplasm can be used in selections with gene based markers. This study identifies the molecular background of response of barley to cold stress, which provides the increased ability to tolerate cold in this plant by genetic engineering. The next challenge is to identify cool sensors. It has been found that the primary multiple sensors are involved in low temperature sensing and each sensor may distinguish a particular aspect of cold stress. Discovery of the signaling mechanism from these sensors is one of the important goals in complete understanding of the mentioned mechanism.

\section{Acknowledgments}

We would like to thank staff of the Biotechnology Institute, Central Laboratory, Ankara University, Ankara, Turkey, for their assistance and preparation of the instruments and devices.

\section{References}

Ahres M, Gierczik K , Boldizsár A , Vítámvás P, Galiba G (2020) Temperature and Light-Quality-Dependent Regulation of Freezing Tolerance in Barley. Plants. 9:83.

Badawi M, Danyluk J, Boucho B, Houde M, Sarhan F (2007) The $C B F$ gene family in hexaploid wheat and its relationship to the phylogenetic complexity of cereal CBFs. Mol Genet Genomic. 277:533-554.

Campoli C, Matus-Cadiz MA, Pozniak CJ, Cattivelli L, Fowler DB (2009) Comparative expression of Cbf genes in the Triticeae underdifferent acclimation induction temperatures. Mol Genet Genomic. 282:141-152.

Ceccarelli S, Grando S, Van Leur JAG (1995) Barley landraces in the Fertile Crescent offer new breeding options for stress environments. Diversity. 11:112-113.

Chinnusamy V, Zhu J, Zhu JK (2007) Cold stress regulation of gene expression in plants. Trends Plant Sci. 12:444-451.

Crosatti C, Pagani D, Cattivelli L, Stanca AM, Rizza F (2008) Effects of the growth stage and hardening conditions on the association between frost resistance and the expression of the cold induced protein COR14b in barley. Environ Exp Bot. 62:93-100.

Dal Bosco C, Busconi M, Govoni C, Baldi P, Stanca AM, Crosatti C, Bassi R, Cattivelli L (2003) Cor gene expression in barley mutants affected in chloroplast development and photosynthetic electron transport. Plant Physiol. 131: 793802.

Dawson IK, Russell J, Powell W, Steffenson B, Thomas WTB, Waugh R (2015) Barley: a translational model for adaptation to climate change. New Phytol. 206:913-931.

Dhillon T (2012) Molecular and genetic analyses of freezing tolerance in the Triticeae cereals. Graduate school of the Ohio State University by graduate program in horticulture and crop science. The Ohio State University. Doctor of Philosophy thesis.

Dhillon T, Pearce S, Stockinger EJ, Distelfeld A, Li C, Knox AK, Vashegyi I, Vágújfalvi A, Galiba G, Dubcovsky J (2010) Regulation of freezing tolerance and flowering in temperate cereals: the $V R N-1$ connection. Plant Physiol. 153:1846-1858.

Dubouzet JG, Sakuma Y, Ito Y, Kasuga M, Dubouzet EG, Miura $\mathrm{S}$, Seki M, Shinozaki K, Yamaguchi-Shinozaki K (2003) OsDREB genes in rice, Oryza sativa L., encode transcription activators that function in drought, high salt and cold-responsive gene expression. Plant J. 33:751-763.

Eglinton JK, Evans DE, Brown AHD, Langridge P, McDonald G, Jefferies SP, Barr AR (1999) The use of wild barley (Hordeum vulgare ssp spontaneum) in breeding for quality and adaptation. Proceedings of the ninth Australian barley technical symposium. 29:1-6.

Ergon A, Melby TI, Höglind M, Rognli OA (2016) Vernalization requirement and the chromosomal VRN-1-region can affect freezing tolerance and expression of cold-regulated genes in Festuca pratensis. Front Plant Sci. 7:207.

Galiba G, Vágújfalvi A, Li C, Soltész A, Dubcovsky J (2009) Regulatory genes involved in the determination of frost tolerance in temperate cereals. Plant Sci. 176:12-19.

Gozukırmızı N (2003) Pioneering biotechnological works on Hordeum vulgare L. cvs performed in collaboration with the Istanbul University biology department and the TUBITAK Research institute for genetic engineering and biotechnology. Turk J Bot. 27:243-248.

Gulyás Z, Boldizsár A, Novák A, Szalai G, Pál M, Galiba G, Kocsy $G$ (2014) Central role of the flowering repressor ZCCT2 in the redox control of freezing tolerance and the initial development of flower primordia in wheat. BMC Plant Biol. 14:91.

Gupta N, Rathore M, Goyary D, Khare N, Anandhan S, Pande V, Ahmed Z (2012) Marker-free transgenic cucumber expressing Arabidopsis cbf1 gene confers chilling stress tolerance. Biol Plant. 56(1): 57-63.

Holková L, Prášil IT, Bradáčová $M$, Vítámvás $P$, Chloupek $O$ (2009) Screening for frost tolerance in wheat using the expression of dehydrine genes Wcs 120 and $W d h n 13$ at $17^{\circ} \mathrm{C}$. Plant Breed. 128:420-422.

Hsieh TH, Lee JT, Charng YY, Chan MT (2002) Tomato plants ectopically expressing Arabidopsis CBF1 show enhanced resistance to water deficit stress. Plant Physiol. 130:618-26.

Jeknic Z, Pillman KA, Dhillon T, Skinner JS, Veisz O, CuestaMarcos A, Hayes PM, Jacobs AK, Chen THH, Stockinger EJ (2014) Hv-CBF2A overexpression in barley accelerates COR gene transcript accumulation and acquisition of freezing tolerance during cold acclimation. Plant Mol Biol. 84:67-82.

Kalapos B, Novák A, Dobrev $P$, Vítámvás $P$, Marincs $F$, Galiba $G$,Vanková R (2017) Effect of the winter wheat cheyenne $5 a$ substituted chromosome on dynamics of abscisic acid and cytokinins in freezing-sensitive chinese spring genetic background. Front Plant Sci. 8:2033.

Kosová K, Klíma M, Prášil IT, Vítámvás P (2021) COR/LEA Proteins as Indicators of Frost Tolerance in Triticeae: A Comparison of Controlled versus Field Conditions. Plants. 10:789.

Kosová K, Vítámvás P, Planchon S, Renaut J, Vanková R, Prášil IT (2013). Proteome analysis of cold response in spring and winter wheat (Triticum aestivum) crowns reveals similarities 
in stress adaptation and differences in regulatory processes between the growth habits. J Proteome Res. 12:4830-4845.

Kruse EB, Revolinski S, Aplin J, Skinner DZ, Murray TD, Edwards CG, Carter AH (2020) Carbohydrate Accumulation and Differential Transcript Expression in Winter Wheat Lines with Different Levels of Snow Mold and Freezing Tolerance after Cold Treatment. Plants. 9:1416.

Livak KJ, Schmittgen TD (2001) Analysis of relative gene expression data using real-time quantitative PCR and the 2$\triangle \triangle C T$ method. Methods. 25:402-408.

Loukoianov A, Yan L, Blechl A, Sanchez A, Dubcovsky J (2005) Regulation of $V R N-1$ vernalization genes in normal and transgenic polyploid wheat. Plant Physiol. 138:2364-2373.

Morran S, Eini O, Pyvovarenko T, Parent B, Singh R, Ismagul A, Eliby $S$, Shirley N, Langridge $P$, Lopato $S$ (2011) Improvement of stress tolerance of wheat and barley by modulation of expression of $D R E B / C B F$ factors. Plant Biotechnol J. 9:230249.

Novak A, Boldizsar A, Adam E, Kozma-Bognar L, Majlath I, Baga M , Toth B , Chibbar R , Galiba G (2016) Light-quality and temperature-dependent CBF14 gene expression modulates freezing tolerance in cereals. J Exp Bot. 67(5):1285-1295.

Oliver SN, Deng W, Casao MC, Trevaskis B (2013) Low temperatures induce rapid changes in chromatin state and transcript levels of the cereal Vernalization1 gene. J Exp Bot. 64(8):2413-2422.

Park C, Seo Y, Park C (2015) Heat shock proteins: a review of the molecular chaperones for plant immunity. Plant Pathol J. 31:323-333.

Pecchioni $N$, Kosová $K$, Vítámvás $P$, Prášil IT, Milc J A, Francia $E$, Gulyás Z, Kocsy G, Galiba G (2014) Genomics of lowtemperature tolerance for an increased sustainability of wheat and barley production. In: Tuberosa R, Graner A, Frison E (ed) Genomics of Plant Genetic Resources, Springer, Dordrecht. 149-183.

Rimpau I, Smith DB, Flavel RB (1980) Sequence organization in barley and oats chromosomes revealed by interspecies DNA/DNA hybridization. Heredity. 44:131-149.
Schmid K, Kilian B, Russell J (2018) Barley domestication, adaptation and population genomics. In: The Barley Genome, Springer, Berlin. 317-336.

Shahmoradi S, Mozafari J (2015) Drought adaptations in wild barley (Hordeum spontaneum) grown in Iran. IJGPB. 4(1):1-9.

Sheidai M, Jaffari F, Keshavarzi M, Noormohammadi Z (2009) Species Relationships in Hordeum: Cytology and RAPD Analyses. Cytologia. 74(3):301-310.

Skinner JS, Szucs P, von Zitzewitz J, Marquez-Cedillo L, Filichkin T, Stockinger EJ, Thomashow MF, Chen TH, Hayes PM (2006) Mapping of barley homologs to genes that regulate low temperature tolerance in Arabidopsis. Theor Appl Genet. 112:832-842.

Soltész A, Smedley M, Vashegyi I, Galiba G, Harwood W, Vágújfalvi A (2013) Transgenic barley lines prove the involvement of TaCBF14 and TaCBF15 in the cold acclimation process and in frost tolerance. J Exp Bot. 64, 1849-1862.

Tondelli A, Pagani D, Ghafoori IN, Rahimi M, Ataei R, Rizza F, Flavell AJ, Cattivelli L (2014) Allelic variation at $\mathrm{Fr}-\mathrm{H} 1 / \mathrm{Vrn}-\mathrm{H1}$ and $\mathrm{Fr}-\mathrm{H} 2$ loci is the main determinant of frost tolerance in spring barley. Environ Exp Bot. 106:148-155.

Vágújfalvi A, Galiba G, Dubcovsky J, Cattivelli L (2000) Two loci on wheat chromosome $5 \mathrm{~A}$ regulate the differential colddependent expression of the cor14b gene in frost-tolerant and frost-sensitive genotypes. Mol Gen Genet. 263:194-200.

Wang JH, Huang CN (2002) Cryopreservation of Hordeum (Barley). In: Towill LE, Bajaj YPS (ed) Biotechnology in agriculture and forestry, Springer, Berlin. 119-135.

Wang L, Sun X, Luo W, Qian C (2018) Roles of C-repeat binding factors-dependent signaling pathway in jasmonatesmediated improvement of chilling tolerance of post-harvest horticultural commodities. J. Food Qual. 2018:8517018.

Zhu JK (2016) Abiotic stress signaling and responses in plants. Cell. 167:313-324. 